\title{
DRUG-RELATED PROBLEMS IN EMERGENCY DEPARTMENT VISITS AND INTENSIVE CARE UNITS AT HEALTHCARE FACILITIES IN SAUDI ARABIA: A REVIEW OF THE LITERATURE
}

\author{
OMAR YAHYA ALSHARGI ${ }^{1}$, ABUBAKAR IBRAHIM JATAU ${ }^{2}$ AND ABUBAKAR \\ SHA'ABAN ${ }^{3,4^{*}}$ \\ ${ }^{1}$ College of Pharmacy, Riyadh Elm University, Riyadh, Kingdom of Saudi Arabia \\ ${ }^{2}$ School of Pharmacy and Pharmacology, University of Tasmania, Tasmania, Australia \\ ${ }^{3}$ School of Pharmaceutical Sciences, Universiti Sains Malaysia, Pulau Pinang, Malaysia \\ ${ }^{4}$ Department of Clinical Pharmacy and Pharmacy Practice, Faculty of Pharmaceutical \\ Sciences, Ahmadu Bello University, Zaria, Nigeria
}

\section{Published online: 23 November 2021}

To cite this article: OMAR YAHYA ALSHARGI, ABUBAKAR IBRAHIM JATAU \& ABUBAKAR SHA'ABAN (2021) Drug-related problems in emergency departments visits and intensive care units at healthcare facilities in Saudi Arabia: A review of the literature, Malaysian Journal of Pharmaceutical Sciences, 19(2): 153-169. https://doi.org/10.21315/ mjps2021.19.2.10

To link to this article: https://doi.org/10.21315/mjps2021.19.2.10

\section{ABSTRACT}

The burden of drug-related problems (DRPs) is becoming an issue of healthcare concern. It has been responsible for many intensive care unit (ICU) admissions and emergency department (ED) visits in Saudi Arabia. We aim to summarise available data on ED visits and ICU admissions linked to DRPs in Saudi Arabia and provide recommendations for preventive measures. A systematic search of the literature was conducted using PubMed and Google Scholar databases to identify eligible studies. The review included research on ED visits and ICU admissions linked to DRPs performed in Saudi Arabia from the database's inception to January 2020. Study selection, data extraction and assessment were performed based on the Preferred Reporting Items for Systematic Review and MetaAnalysis (PRISMA) guidelines. The initial search of literature generated 267 articles. After the study selection, 15 articles met our eligibility criteria and were included in the review. The commonly implicated DRPs were adverse drug reactions, medication non-adherence, drug overdose and drug interactions. Central nervous system drugs and cardiovascular drugs were the most frequently involved drugs. Most of these visits resulted in moderate harm. The prevalence of DRPs associated with ED visits and ICU admissions is high in Saudi Arabia. Sixteen out of a hundred ED visits and ICU admissions are related to DRPS. Therefore, the Saudi government should implement interventions to improve the awareness of rational drug use in the general public.

"Corresponding author: abuushaaban@usm.my

(c) Penerbit Universiti Sains Malaysia, 2021. This work is licensed under the terms of the Creative Commons Attribution (CC BY) (http://creativecommons.org/licenses/by/4.0/). 
Keywords: Drug-related problems, Emergency department, Intensive care units, Drugs, Saudi Arabia

\section{INTRODUCTION}

Drug-related problems (DRPs) is defined by the Pharmaceutical Care Network Europe (PCNE) as 'an event or circumstance involving drug therapy that actually or potentially interferes with the desired health outcome' (PCNE 2017). A DRP that has not been detected and addressed could increase mortality, morbidity and healthcare costs. Previous studies have shown that DRPs are of significant public health problem concern in the general population. The incidence of DRPs leading to hospitalisation has been reported to be as high as $24 \%$ (Zed 2005). It has been estimated that morbidity and mortality associated with DRPs account for 17 million emergency department (ED) visits and 8.7 million hospital admissions (Anderson et al. 2002). This burden accounts for the in-hospital cost of USD76.6 billion to more than USD177.4 billion between 1995 and 2000 (Anderson et al. 2002). It may be difficult in the developing countries to obtain national data on DRP-linked burden due to inadequate national surveillance systems and limited studies on DRPs.

In Saudi Arabia, available data shows that DRP occurrences leading to hospitalisation are common in the general public (Alsaidan et al. 2018). This frequent occurrences of DRP could be associated to widespread irrational use of both prescription and over the counter (OTC) medication in the general population as many prescriptions only medicines (POM) are purchased without a valid prescription in the Kingdom of Saudi Arabia (KSA) (Alsaidan et al. 2018). Therefore, addressing the DRPs-linked burden has become a public health priority, given the increasing use of medication and chronic diseases.

ED is one of the hospital settings that cater to patients with acute medical conditions. A high prevalence of DRPs-related ED visits indicates how serious the burden of DRP is in the community (Jatau et al. 2019; Bakhaidar et al. 2015; Alanazi, Al-Jeraisy and Salam 2015). Several studies have been conducted to assess the burden of DRPslinked to ED visits and intensive care units (ICU) admissions at various healthcare centres in KSA (Alghamdy et al. 2015). A summary of these studies will provide a comprehensive representation of what has been explored in KSA. It will help identify the literature gaps that would guide the design and implementation of interventions to reduce the harm associated to medication use in clinical practice and the general public. Therefore, we aimed to summarise studies on DRPs-linked to ED and ICU conducted at healthcare facilities in KSA and make recommendations for targeted interventions.

\section{METHODS}

\section{Literature Search}

The literature was searched to identify studies conducted on DRPs-linked ED visits and ICU admissions at KSA healthcare facilities. The search was performed using Medline via PubMed database. Other relevant articles were identified through Google Scholar and manual search of the reference lists of included articles. For the Google Scholar search, the first 200 search results, sorted according to the relevance ranking were considered for inclusion, based on a previous recommendation (Bramer et al. 2017). The search strategies used for the selected databases are provided in Appendix A.

Malay J Pharm Sci, Vol. 19, No. 2 (2021): 153-169 


\section{Eligibility Criteria}

Peer-reviewed articles written in the English language from the inception of the databases to January 2020 were eligible for inclusion based on the following criteria: a) studies on any DRPs-linked visit to ED or ICU, b) studies conducted at the EDs or ICU of healthcare facilities in Saudi Arabia and c) any patient population. Studies were excluded if performed in other hospital units/wards (for example, outpatient departments, inpatient wards or other units outside ED and ICU). Also, studies that are explicitly reporting illicit drugs use or their untoward effects were excluded.

In this study, ED visits or ICU admissions linked to DRPs refers to any visit to the ED or ICU with a primary complain due to DRPs, such as adverse drug reactions (ADR), medication error (ME), medication non-adherence, sub-therapeutic dose, overdosage, therapeutic drug failure and wrong drug selection.

\section{Literature Selection}

Articles obtained from the systematic search were exported to EndNote X8 TM (Clarivate Analytics, Philadelphia, USA), where the duplicate studies were identified and excluded. The full texts of the articles were assessed for eligibility following screening for titles and abstracts.

\section{Data Extraction and Assessment}

The following information was extracted from the included studies: author/publication year, study design, sample size, the prevalence of DRPs-linked ED visits, common drugs reported, class of DRPs involved, and outcomes of the ED visits or ICU admissions. The summary of the data extracted is presented in Table 1. This review was conducted and reported based on the Preferred Reporting Items for Systematic Review and Meta-Analysis (PRISMA) checklist.

\section{RESULTS}

\section{Search Results}

The initial search of the literature from the two databases generated 267 records and four relevant articles were obtained through a manual search of included studies. The screening for duplicates removed 18 articles and 153 articles were excluded during the title and abstract screening. A total of 81 articles were excluded based on the eligibility criteria. Finally, 15 articles that met up the eligibility criteria were included in this study. Figure 1 demonstrates the literature selection process using the PRISMA flowchart. 


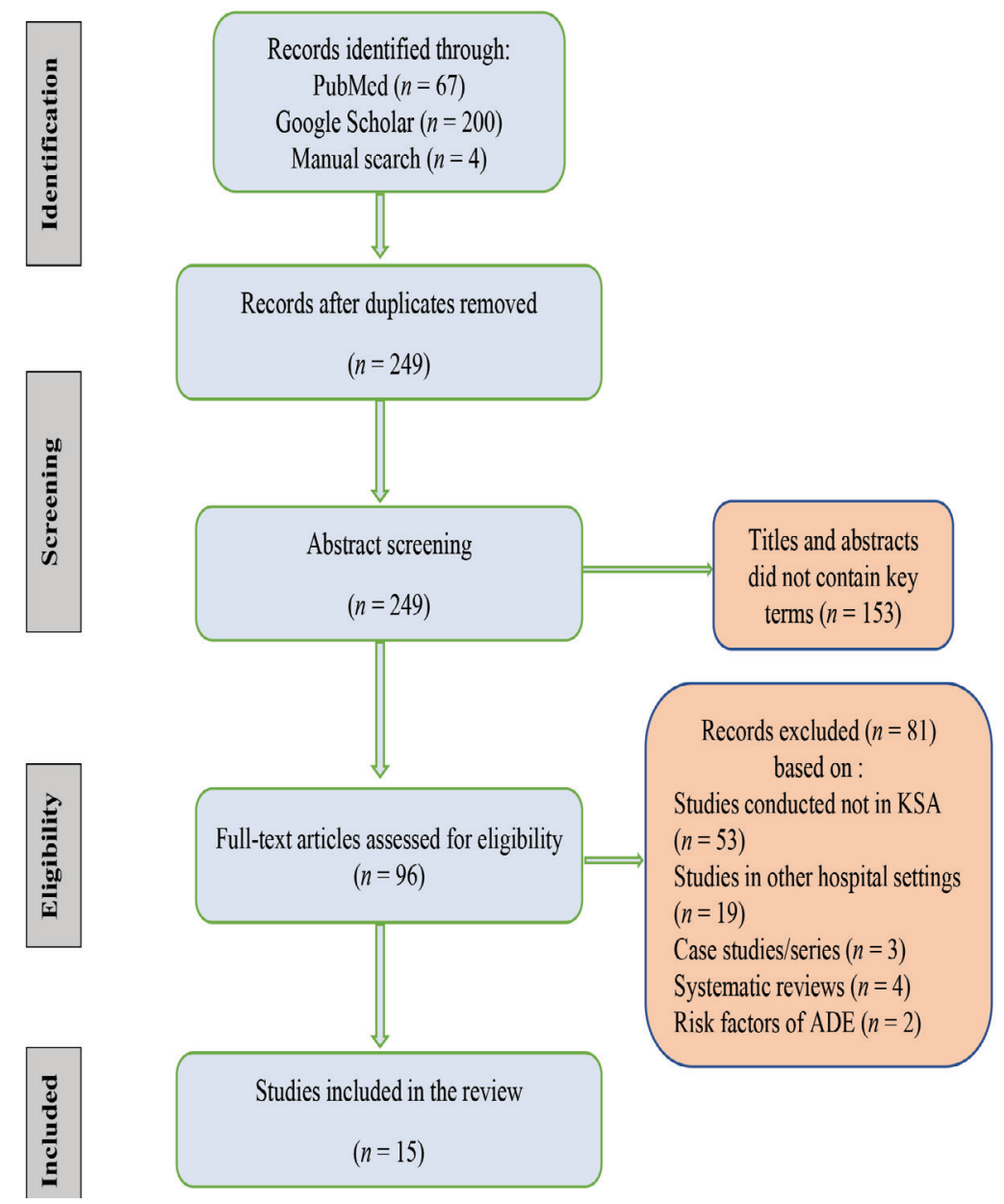

Figure 1: PRISMA flow diagram illustrating the literature screening process.

\section{Description of Included Studies}

Of the 15 studies included, 9 were prospective cohort study design (AlAzmi et al. 2019; Ragab and Al-Mazroua 2015; Mohamed 2014; Al-Arifi et al. 2014; Rashed et al. 2012; Al-Hazmi 1998; Al-Olah and Al-Thiab 2008; Al-Sekait 1990; Alayed et al. 2019); five were retrospective case review (Alghadeer et al. 2018; Mantas 2017; Randhawa et al. 2015; Alghamdy et al. 2015; Bakhaidar et al. 2015) and one cross-sectional study (Alanazi, AlJeraisy and Salam 2015). Generally, all the studies were conducted in four major cities, namely Riyadh (seven studies: Al-Sekait 1990; Al-Olah and Al Thiab 2008; Rashed et al. 2012; Al-Arifi et al. 2014; Mohamed 2014; Mantas 2017; Alghadeer et al. 2018), Jeddah (four studies: AlAzmi et al. 2019; Alanazi, Al-Jeraisy and Salam 2015; Bakhaidar et al. 2015; Al-Hazmi 1998), Dammam (three studies: Randhawa et al. 2015; Alghamdy et al. 2015; Ragab and Al-Mazroua 2015) and Unaizah (one study: Alayed et al. 2019). In terms of the study settings, four were conducted in ICU (Randhawa et al. 2015; Rashed et al. 
2012; Mohamed 2014; Ragab and Al-Mazroua 2015), eight were performed at ED (Alayed et al. 2019; Alghadeer et al. 2018; Mantas 2017; Alghamdy et al. 2015; Alanazi, Al-Jeraisy and Salam 2015; Bakhaidar et al. 2015; Al-Olah and Al Thiab 2008; Al-Arifi et al. 2014), while two were conducted at both ED and ICU (AIAzmi et al. 2019; Al-Hazmi 1998). One of the studies was not specific in terms of setting (Al-Sekait 1990). Six of the studies were conducted in children population (Alghadeer et al. 2018; Ragab and Al-Mazroua 2015; Rashed et al. 2012; Al-Hazmi 1998; Al-Sekait 1990; AlAzmi et al. 2019). All the studies were conducted in tertiary healthcare facilities.

\section{Prevalence of DRPs in the ED/ICU}

The studies were heterogeneous in terms of research outcomes, with some focusing on general DRPs, while others on a specific type of DRP. This heterogeneity will make the study comparison difficult. Seven of the studies focused on all kinds of DRP and reported a prevalence in the range of $3.6 \%$ to $35.9 \%$ (AlAzmi et al. 2019; Mantas 2017; Randhawa et al. 2015; Mohamed 2014; Al-Arifi et al. 2014; Rashed et al. 2012; Al-Olah and Al Thiab 2008). Seven studies assessed the individual type of DRP, namely poisoning, mostly among paediatric population 4.9\% to 7.2\% (Al-Sekait 1990; Al-Hazmi 1998; Bakhaidar et al. 2015; Ragab and Al-Mazroua 2015; Alghadeer et al. 2018), prescription error (46.2\%) (Alanazi, Al-Jeraisy and Salam 2015) and ADR (0.8\%) (Alayed et al. 2019). Overall, the prevalence of DRPs from all the included is $16.0 \%$. Table 1 illustrates the prevalence of DRPs-linked $\mathrm{ED} / \mathrm{ICU}$ at healthcare facilities in KSA. 


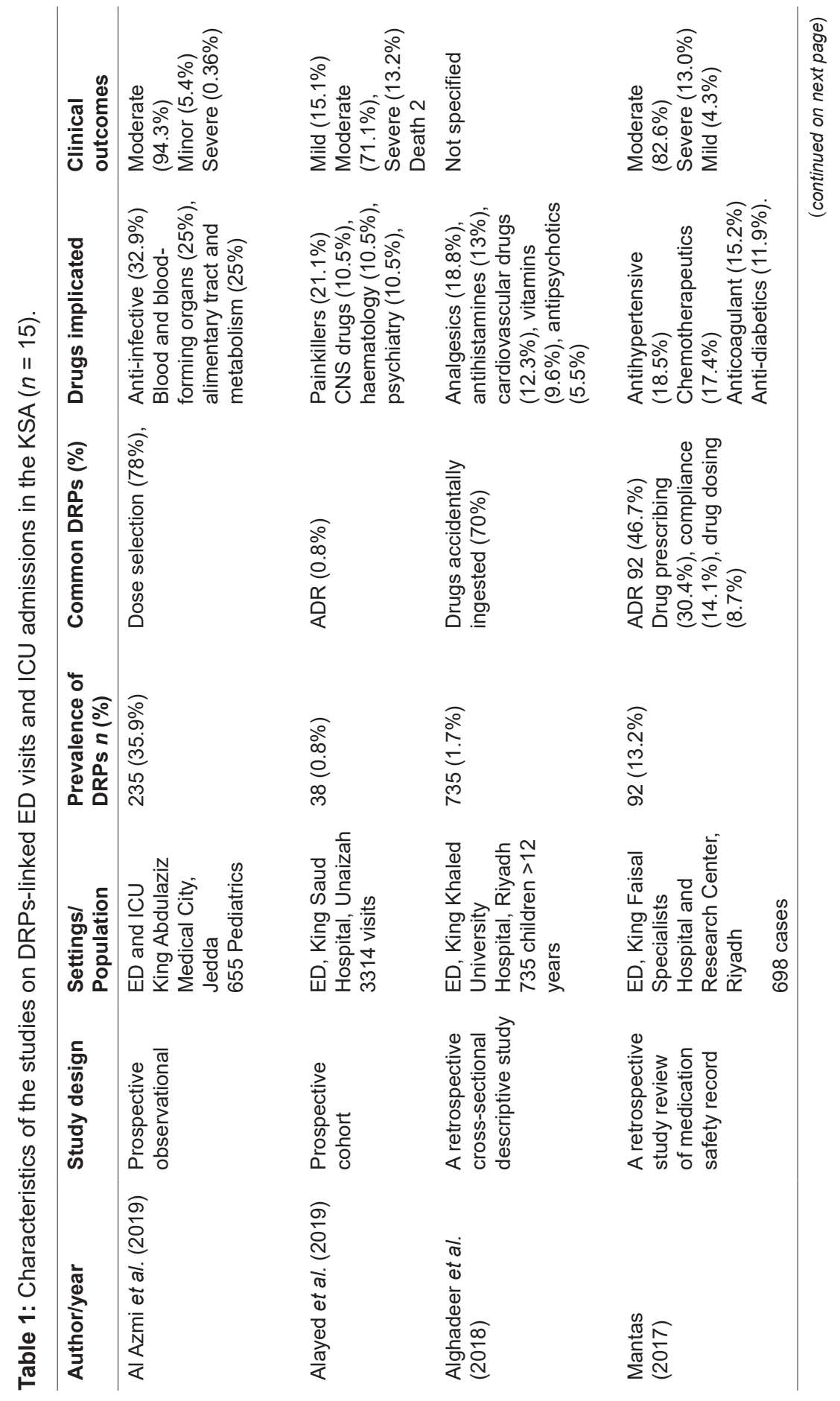

Malay J Pharm Sci, Vol. 19, No. 2 (2021): 153-169 


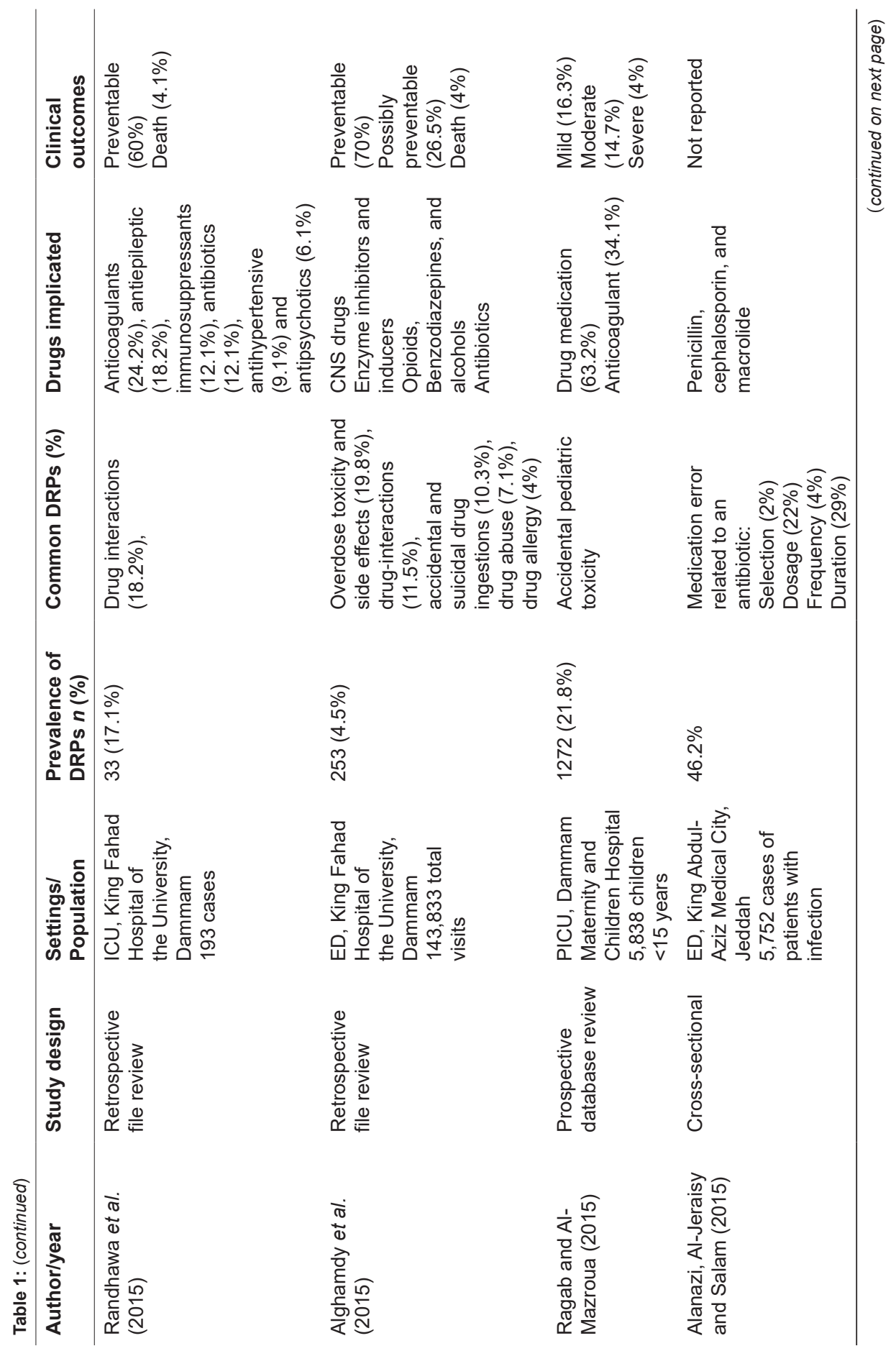

Malay J Pharm Sci, Vol. 19, No. 2 (2021): 153-169 


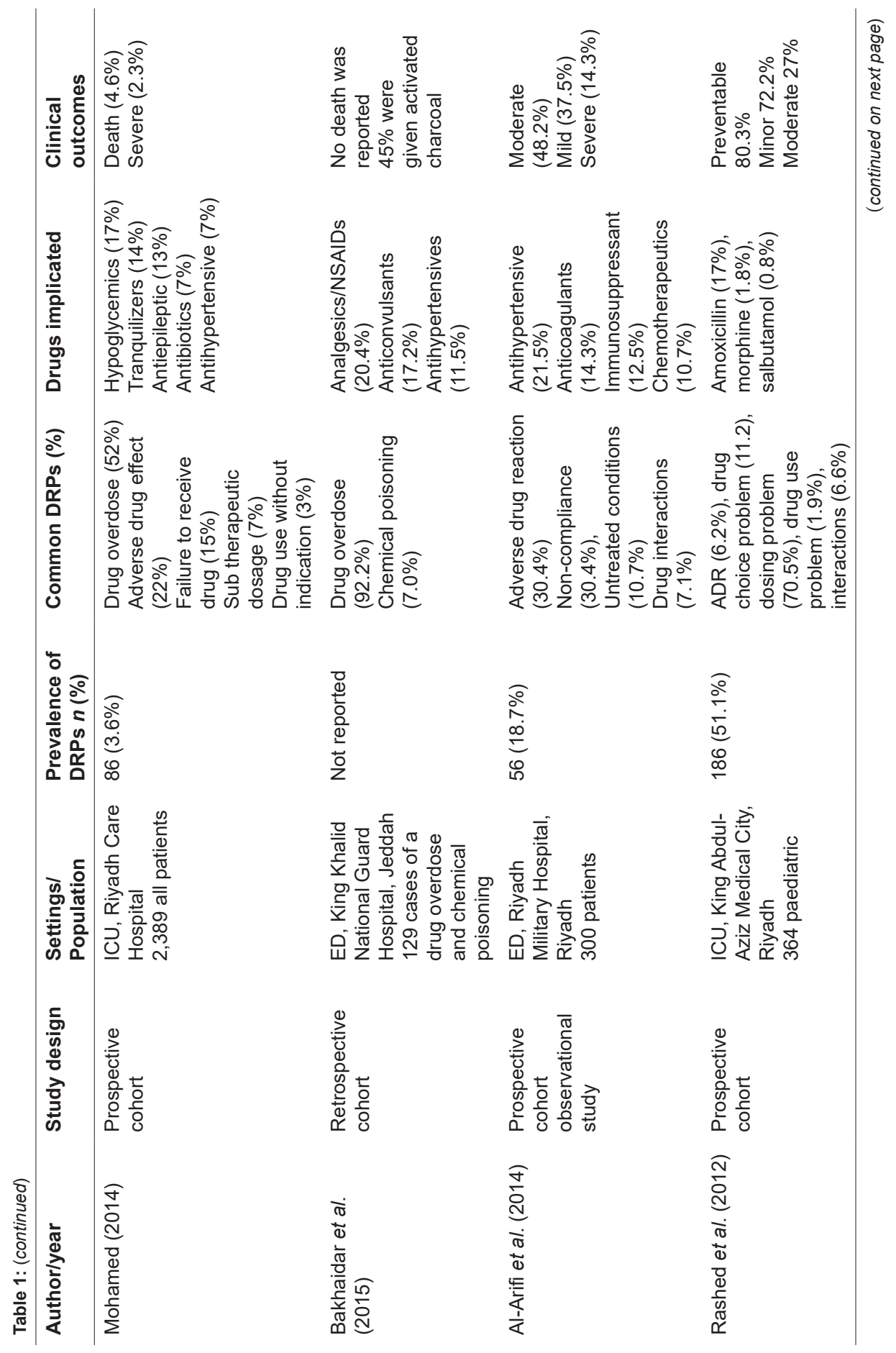

Malay J Pharm Sci, Vol. 19, No. 2 (2021): 153-169 


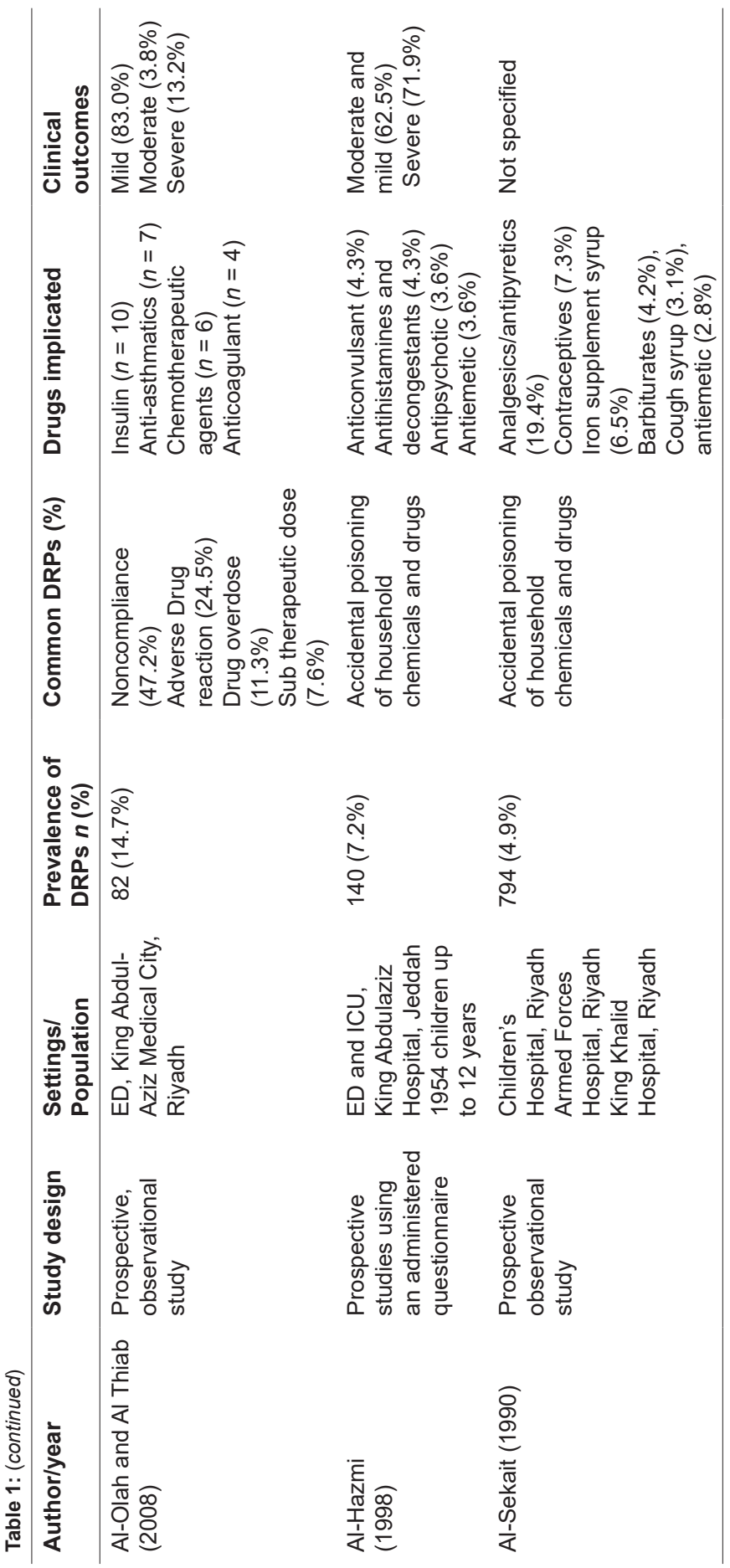

Malay J Pharm Sci, Vol. 19, No. 2 (2021): 153-169 


\section{Common Types of DRPs Identified}

The most common DRPs reported by the studies that focused on all DRPs were ADRs, reported by five out of the seven studies (5/7), medication non-adherence (4/7), medication overdose (4/7) and medication interactions (4/7). Other DRPs reported were sub-therapeutic doses, untreated indications, drug allergy, and drug selection (Table 1). As high as $46.7 \%$ prevalence of ADR and medication non-adherence were reported, respectively (Al-Arifi et al. 2014; Mantas 2017). A higher prevalence of $52 \%$ of medication overdose and $18.2 \%$ of medication interactions were reported by previous researchers (Mohamed 2014; Randhawa et al. 2015).

\section{Drug Classes Most Frequently Involved}

The most common classes of medications implicated in the DRPs-linked ED visits and ICU admissions included central nervous system (CNS) drugs such as tranquilisers and anti-epileptics, reported by nine studies $(n=9)$. Others include analgesics/non-steroidal anti-inflammatory drugs (NSAIDs) $(n=6)$, antibiotics $(n=6)$, cardiovascular system (CVS) such as antihypertensives $(n=6)$, anticoagulants $(n=5)$, chemotherapeutic agents $(n=5)$, anti-diabetics including insulin $(n=3)$ and antipsychotics $(n=3)$. A high percentage $(34.1 \%)$ of DRPs linked specifically to ICU admission was due to anticoagulant use (Ragab and Al-Mazroua 2015). Antibiotics account for up to $33 \%$ of the DRPs in a study by AlAzmi et al. (2019). Anti-hypertensives (CVS drug class) were involved in $21.5 \%$ of cases of DRPs in a study by Al-Arifi et al. (2014). Analgesics/NSAIDs were frequent in as high as $20.4 \%$ of DRPs in a retrospective study in Jeddah (Bakhaidar et al. 2015).

\section{Clinical Outcomes}

The injury caused due to the DRPs in this review was classified into severe, moderate and minor. Cases of death linked to the DRPs were also recorded. Most (up to 94.3\%) of the ED visits' clinical outcomes due to the DRPs were moderate (AIAzmi et al. 2019). In a study focusing on poisoning cases among children 12 years and below, DRPs resulted in $71.9 \%$ severe outcomes (Al-Hazmi 1998). Four studies reported death due to DRPs (Mohamed 2014; Alghamdy et al. 2015; Randhawa et al. 2015; Alayed et al. 2019). In a prospective cohort study conducted at the ICU unit of Riyadh Care Hospital, $4.6 \%$ of death was contributed by DRPs (Mohamed 2014). Three of the studies did not report the level of harm caused by DRPs during the patient visit (Alghadeer et al. 2018; Alanazi, Al-Jeraisy and Salam 2015; Al-Sekait 1990). The majority of the DRPs were preventable. Rashed et al. (2012) reported that $80.3 \%$ of DRPs-linked ED visits were preventable (Rashed et al. 2012).

\section{DISCUSSION}

The current study summarises the literature on ED visits and ICU admissions linked to DRPs at KSA healthcare facilities. Prevalence from the included studies suggests that 1 out of 16 ED visits at healthcare institutions in KSA is related to DRPs. This finding is comparable to a previous study by Zed (2005). This shows that the burden of DRP is high in KSA and thus calls for interventional measures to improve patient safety and reduce healthcare costs.

Malay J Pharm Sci, Vol. 19, No. 2 (2021): 153-169 
Fortunately, up to $80 \%$ of the DRPs reported were preventable. This preventability further illustrates the possibility of interventions to prevent further occurrences.

ADR was the most common DRP reported to be associated with ED visits. A population-based study in KSA showed that more than $25 \%$ of the population had experienced ADR in the last 12 months (Almubark et al. 2019). The reported high incidence of ADR among the general population in KSA may explain our findings. Further, ADR under-reporting in KSA may also be a reason for the high ADR rate reported in this study. Intervention to improve ADR reporting at a large tertiary hospital has been trialled in KSA. Ali et al. (2018) used incentives to enhance ADR reporting over two years. At the end of their study period, the number of ADR reports per month increased by $40.6 \%$ (Ali et al. 2018).

The high frequency of medication non-adherence may be related to the increasing rate of chronic diseases in KSA (Mokdad 2014). Medication non-adherence has been common among people with chronic conditions in the KSA (Alkhamis et al. 2019; AIQarni et al. 2019). Medication overdose was commonly implicated in many studies. This is a severe problem that requires an urgent intervention among the general population in KSA. An epidemiological data covering a 5-year assessment of medication overdose shows a higher rate of medication overdose in KSA (Al-Jaser, Epi and Awofeso 2013). The high frequency of this problem may also be explained by the widespread nonmedical use of prescription drugs (Martins and Ghandour 2017) and limited provision of poison information services by the Drug Information Centers (DICs) and Drug and Poison Information Centers (DPICs) in KSA (AINasser, Khojah and AIQahtani 2019). Interventions targeted at improving the level of awareness are needed to prevent this burden.

The most involved drugs in ED visits and ICU admissions were CNS, CVS, analgesic/NSAIDs, antibiotics and anticoagulants. These classes of drugs have been previously identified to be widely involved in ED visits related to drugs (Jatau, Aung and Kamauzaman 2015). These medications are among the top 10 most used drugs in KSA (AlKhamees et al. 2018). And despite the existing laws, these drugs are sold in community pharmacies without a valid prescription in KSA (AlKhamees et al. 2018). This further contributes to the self-medication and potentially leading to ED visits due to DRP. Improved patient education, counselling and enforcement of drug laws may prevent this burden.

Cardiovascular and CNS disorders were the most presented diagnoses among the patients in this review. Others include gastrointestinal disorders, followed by respiratory ailments. The high rate of cardiovascular and CNS disorders could be due to accidental chemicals and poison ingestion and non-compliance with medication. The high number of cardiovascular patients in this study could be related to the previously reported high prevalence of cardiovascular and CNS diseases in KSA (Kumosani, Alama and lyer 2011; AlKhamees et al. 2018; Tyrovolas et al. 2020). Increased risk of drug abuse is usually associated with CNS drugs among patients, as reported in previous studies. It could be the reason for the high rate of DRPs due to CNS drugs identified (Ibrahim et al. 2018).

\section{Interventions}

According to the UK National Institute for Health and Care Excellence, successful implementation of intervention should be guided by a conceptual framework (National Institute for Health and Care Excellence 2014). Therefore, sustainable interventions to prevent ED visits related to DRPs in KSA should be designed and implemented based on a conceptual framework. Jatau et al. (2019) developed a conceptual model that would guide the design and implementation of interventions to prevent DRPs leading to ED (Jatau 
et al. 2019). According to the model, interventions should be targeted at factors related to patients' sociodemographic characteristics, community, healthcare settings, policy and healthcare personnel (Jatau et al. 2019).

Sociodemographic factors such as level of education, patients knowledge of medication use, improving the awareness and understanding of patients through counselling, and the use of beer's criteria screening tools can help reduce DRPs (Panel et al. 2019). Therefore, providing appropriate information to patients (especially the young or aged), awareness of drug misuse and abuse, and providing more primary healthcare facilities for easy patient access will significantly reduce ED visits and ICU admissions due to DRPs.

The second aspect of the intervention is improving patients' clinical factors, which involves looking into the patient's clinical characteristics, such as chronic diseases and multiple diseases, which may lead to polypharmacy. Polypharmacy leads to drug interactions and adverse drug reactions (Hayes, Klein-Schwartz and Barrueto 2007). Screening Tool of Older People's Prescriptions, the Screening Tool to Alert to Right Treatment (STOPP/ START), Computerised Physician Order Entry (CPOE) and the use of Telemedicine are some of the essential clinical interventions to assist clinicians and patients in making the best decisions to reduce the rate of DRPs (Brown et al. 2016).

Another vital aspect of the intervention is through research and development. A valuable data gathering, pharmacovigilance surveillance, and more studies on the event can give a clearer picture, rate and associated factors of the DRPs. This will help in having more effective interventions to reduce the rate of DRPs presented in the ED.

\section{Strengths and Limitations}

This review is among the first in KSA to compile studies on ED visits and ICU admissions linked to DRPs and give a unified picture of the problem. It will further help decision-makers in identifying appropriate solutions and interventions to the problem. However, there are not enough studies in the KSA to give a broader picture of the incidence.

\section{CONCLUSION}

The prevalence of ED visits and ICU admissions linked to DRPs is widespread and a significant public health problem in KSA. ADR, medication non-adherence, medication overdose and medication interactions were the most reported DRPs related to ED visits and ICU admissions in KSA. Anticoagulants, anti-diabetics, antibiotics and medications that affect the CNS and CVS were the most frequently implicated drug classes in ED visits and ICU admissions. Fortunately, about $80 \%$ of the DRPs were preventable. Therefore, there is a need for sustainable interventions targeting the general public, patients, healthcare systems and healthcare personnel to prevent DRPs and improve clinical outcomes in KSA.

\section{REFERENCES}

AL-ARIFI, M., ABU-HASHEM, H., AL-MEZINY, M., SAID, R. \& ALJADHEY, H. (2014) Emergency department visits and admissions due to drug related problems at Riyadh Military Hospital (RMH), Saudi Arabia, Saudi Pharmaceutical Journal, 22: 17-25. https://doi.org/10.1016/j.jsps.2013.01.001

Malay J Pharm Sci, Vol. 19, No. 2 (2021): 153-169 
AL-HAZMI, A. M. (1998) Patterns of accidental poisoning in children in Jeddah, Saudi Arabia, Annals of Saudi Medicine, 18: 457-459. https://doi.org/10.5144/0256-4947.1998.457

AL-JASER, N., EPI M. C. \& AWOFESO, N. (2013) Epidemiology of patients diagnosed with prescription and non-prescription drug overdose at the Riyadh Security Forces Hospital between January 2007 and December 2011. IN: A. J. Rodriguez-Morales (Ed.). Current topics in public health, pp. 593-622 (InTech) https://doi.org/10.5772/52879

AL-OLAH, Y. H. \& AL THIAB, K. M. (2008) Admissions through the emergency department due to drug-related problems, Annals of Saudi Medicine, 28(6): 426-429. https://doi. org/10.5144/0256-4947.2008.426

AL-SEKAIT, M. A. (1990) Epidemiology of accidental poisoning of children in Riyadh, Saudi Arabia, Annals of Saudi Medicine, 10(3): 276-279. https://doi.org/10.5144/02564947.1990.276

ALANAZI, M. Q., AL-JERAISY, M. I. \& SALAM, M. (2015) Prevalence and predictors of antibiotic prescription errors in an emergency department, Central Saudi Arabia, Drug, Healthcare and Patient Safety, 7: 103. https://doi.org/10.2147/DHPS.S83770

ALAYED, N., ALKHALIFAH, B., ALHARBI, M., ALWOHAIBI, N. \& FAROOQUI, M. (2019) Adverse drug reaction (ADR) as a cause of hospitalisation at a government hospital in Saudi Arabia: A prospective observational study, Current Drug Safety, 14(3): 192-198. https://doi.org/10.2174/1574886314666190520105330

ALAZMI, A., AHMED, O., ALHAMdAN, H., ALGARNI, H., ELZAIN, R. M., ALTHUBAITI, R. S. et al. (2019) Epidemiology of preventable drug-related problems (DRPs) among hospitalised children at KAMC-Jeddah: A single-institution observation study, Drug, Healthcare and Patient Safety, 2019: 95-103. https://doi.org/10.2147/DHPS.S220081

ALGHADEER, S., ALROHAIMI, M., ALTHIBAN, A., KALAGI, N. A., BALKHI, B. \& KHAN, A. A. (2018) The patterns of children poisoning cases in community teaching hospital in Riyadh, Saudi Arabia, Saudi Pharmaceutical Journal, 26: 93-97. https://doi.org/10.1016/j. jsps.2017.10.007

ALGHAMDY, M. S., RANDHAWA, M. A., AL-WAHHAS, M. H. \& AL-JUMAAN, M. A. (2015) Admissions for drug-related problems at the Emergency Department of a University Hospital in the Kingdom of Saudi Arabia, Journal of Family and Community Medicine, 22(1): 44-48. https://doi.org/10.4103/2230-8229.149590

ALI, S., EGUNSOLA, O., AL-DOSSARI, D. S. \& AL-ZAAGI, I. A. (2018) Adverse drug reaction reporting in a large tertiary hospital in Saudi Arabia: Results of an incentive strategy, Therapeutic Advances in Drug Safety, 9: 585-590. https://doi. org/10.1177/2042098618790209

ALKHAMEES, O. A., ALNEMER, K. A., BIN MANEEA, M. W., ALSUGAIR, F. A., ALENIZI, B. H. \& ALHARF, A. A. (2018) Top 10 most used drugs in the Kingdom of Saudi Arabia 2010-2015, Saudi Pharmaceutical Journal, 26(2): 211-216. https://doi.org/10.1016/j. jsps.2017.12.009 
ALKHAMIS, A. M., ALSAlmAN, A. J., AL KHAMIS, M., ALKHAMIS, A. \& ALOTAIBI, N. M. (2019) Prevalence of nonadherence to antihypertensive medications among adults attending primary healthcare clinics in Al-Hasa region: A cross-sectional study, Dr. Sulaiman Al Habib Medical Journal, 1(1-2): 36-43. https://doi.org/10.2991/dsahmj.k.190516.001

ALMUBARK, R. A., ALSHAMMARI, T. M., ALQAHTANI, A. S. \& BINDHIM, N. F. (2019) Population-based estimates of community-based adverse drug reactions (ADRS) in the Kingdom of Saudi Arabia, Food and Drug Regulatory Science Journal, 2: 1-1. https://doi. org/10.32868/rsj.v2i1.24

ALNASSER, S. N., KHOJAH, N. \& ALQAHTANI, S. A. (2019) Assessment of drug and poison information centers in Saudi Arabia, Toxicology Communications, 3: 43-46. https:// doi.org/10.1080/24734306.2019.1624410

ALQARNI, K., ALQARNI, E. A., NAQVI, A. A., ALSHAYBAN, D. M., GHORI, S. A., HASEEB, A. et al. (2019) Assessment of medication adherence in Saudi patients with type ii diabetes mellitus in Khobar City, Saudi Arabia, Frontiers in Pharmacology, 10: 1-9. https://doi. org/10.3389/fphar.2019.01306

ALSAIDAN, J., PORTLOCK, J., ALJADHEY, H. S., SHEBL, N. A. \& FRANKLIN, B. D. (2018) Systematic review of the safety of medication use in inpatient, outpatient and primary care settings in the Gulf Cooperation Council countries, Saudi Pharmaceutical Journal, 26(7): 977-1011. https://doi.org/10.1016/j.jsps.2018.05.008

ANDERSON, J. G., JAY, S. J., ANDERSON, M. \& HUNT, T. J. (2002) Evaluating the capability of information technology to prevent adverse drug events: A computer simulation approach, Journal of the American Medical Informatics Association, 9(5): 479-490. https:// doi.org/10.1197/jamia.M1099

BAKHAIDAR, M., JAN, S., FARAHAT, F., ATTAR, A., ALSAYWID, B. \& ABUZNADAH, W. (2015) Pattern of drug overdose and chemical poisoning among patients attending an emergency department, Western Saudi Arabia, Journal of Community Health, 40: 57-61. https://doi.org/10.1007/s10900-014-9895-x

BRAMER, W. M., RETHLEFSEN, M. L., KLEIJNEN, J. \& FRANCO, O. H. (2017) Optimal database combinations for literature searches in systematic reviews: A prospective exploratory study, Systematic Reviews, 6: 245. https://doi.org/10.1186/s13643-017-0644-y

BROWN, J. D., HUTCHISON, L. C., LI, C., PAINTER, J. T. \& MARTIN, B. C. (2016) Predictive validity of the beers and screening tool of older persons' potentially inappropriate prescriptions (STOPP) criteria to detect adverse drug events, hospitalisations, and emergency department visits in the United States, Journal of the American Geriatrics Society, 64(1): 22-30. https://doi.org/10.1111/jgs.13884

HAYES, B. D., KLEIN-SCHWARTZ, W. \& BARRUETO JR, F. (2007) Polypharmacy and the geriatric patient, Clinics in Geriatric Medicine, 23(2): 371-390. https://doi.org/10.1016/j. cger.2007.01.002 
IBRAHIM, Y., HUSSAIN, S. M., ALNASSER, S., ALMOHANDES, H. \& SARHANDI, I. (2018) Patterns and sociodemographic characteristics of substance abuse in Al Qassim, Saudi Arabia: A retrospective study at a psychiatric rehabilitation center, Annals of Saudi Medicine, 38(5): 319-325. https://doi.org/10.5144/0256-4947.2018.319

JATAU, A. I., AUNG, M. M. T. \& KAMAUZAMAN, T. H. T. (2015) Prevalence of drugrelated emergency department visits at a teaching hospital in Malaysia, Drugs-Real World Outcomes, 2: 387-395. https://doi.org/10.1007/s40801-015-0045-2

JATAU, A. I., SHITU, Z., KHALID, G. M., YUNUSA, I. \& AWAISU, A. (2019) Understanding adverse drug-related emergency department visits: Development of a conceptual model through a systematic review. Therapeutic Advances in Drug Safety, 10: 1-18. 2042098619852552. https://doi.org/10.1177/2042098619852552

KUMOSANI, T. A., ALAMA, M. N. \& IYER, A. (2011) Cardiovascular diseases in Saudi Arabia. Prime Research in Medicine, 1, 1-6.

MANTAS, I. E. H. T. J. (2017) Medications related emergency admissions: Causes and recommendations. Informatics Empowers Healthcare Transformation, 238, 169.

MARTINS, S. S. \& GHANDOUR, L. A. (2017) Nonmedical use of prescription drugs in adolescents and young adults: Not just a Western phenomenon, World Psychiatry, 16(1): 102-104. https://doi.org/10.1002/wps.20350

MOHAMED, K. A. (2014). Pattern of intensive care unit admission due to drug problems. Medical Journal of Cairo University, 82: 163-168.

MOKDAD, A. 2014. Saudi Health Interview Survey finds high rates of chronic diseases in the Kingdom of Saudi Arabia.

NATIONAL INSTITUTE FOR HEALTH AND CARE EXCELLENCE. (2014) Behaviour change:Individual approaches (PH49) [Online]. Available: http://guidance.nice.org.uk/PH49 (29 May 2019).

PANEL, A. G. S. B. C. U. E., FICK, D. M., SEMLA, T. P., STEINMAN, M., BEIZER, J., BRANDT, N. et al. (2019) American Geriatrics Society 2019 updated AGS Beers Criteria 8 for potentially inappropriate medication use in older adults, Journal of the American Geriatrics Society, 67(4): 674-694. https://doi.org/10.1111/jgs.15767

PHARMACEUTICAL CARE NETWORK EUROPE (PCNE) (2017) http://www.pcne.org/ working-groups/2/drug-related-problem-classification (January 2020).

RAGAB, A. \& AL-MAZROUA, M. (2015) Pattern of pediatric toxicity in Saudi Arabia-Eastern province (incidence, demographics and predisposing factors), Pediatrics and Therapeutics, 5(1): 1-4. https://doi.org/10.4172/2161-0665.1000220

RANDHAWA, M. A., QUTUB, H. O., ALGHAMDI, M. S., AL-JAIZANI, R. A., MUSHTAQ, R. Y. \& AKBAR, M. J. (2015) Drug related problems at the intensive care unit of a University Hospital in Saudi Arabia, Saudi Journal of Internal Medicine, 5(1): 11-18. https://doi. org/10.32790/sjim.2015.5.1.3 
RASHED, A. N., NEUBERT, A., TOMLIN, S., JACKMAN, J., ALHAMDAN, H., ALSHAIKH, A., et al. (2012) Epidemiology and potential associated risk factors of drug-related problems in hospitalised children in the United Kingdom and Saudi Arabia, European Journal of Clinical Pharmacology, 68: 1657-1666. https://doi.org/10.1007/s00228-012-1302-x

TYROVOLAS, S., EL BCHERAOUI, C., ALGHNAM, S. A., ALHABIB, K. F., ALMADI, M. A. H., AL-RADDADI, R. M. et al. (2020) The burden of disease in Saudi Arabia 1990-2017: Results from the Global Burden of Disease Study 2017, The Lancet Planet Health, 4(5): E195-E208. https://doi.org/10.1016/S2542-5196(20)30075-9

ZED, P. J. (2005) Drug-related visits to the emergency department, Journal of Pharmacy Practice, 18(5): 329-335. https://doi.org/10.1016/S2542-5196(20)30075-9 


\section{APPENDIX A}

The search strategies used for the selected databases.

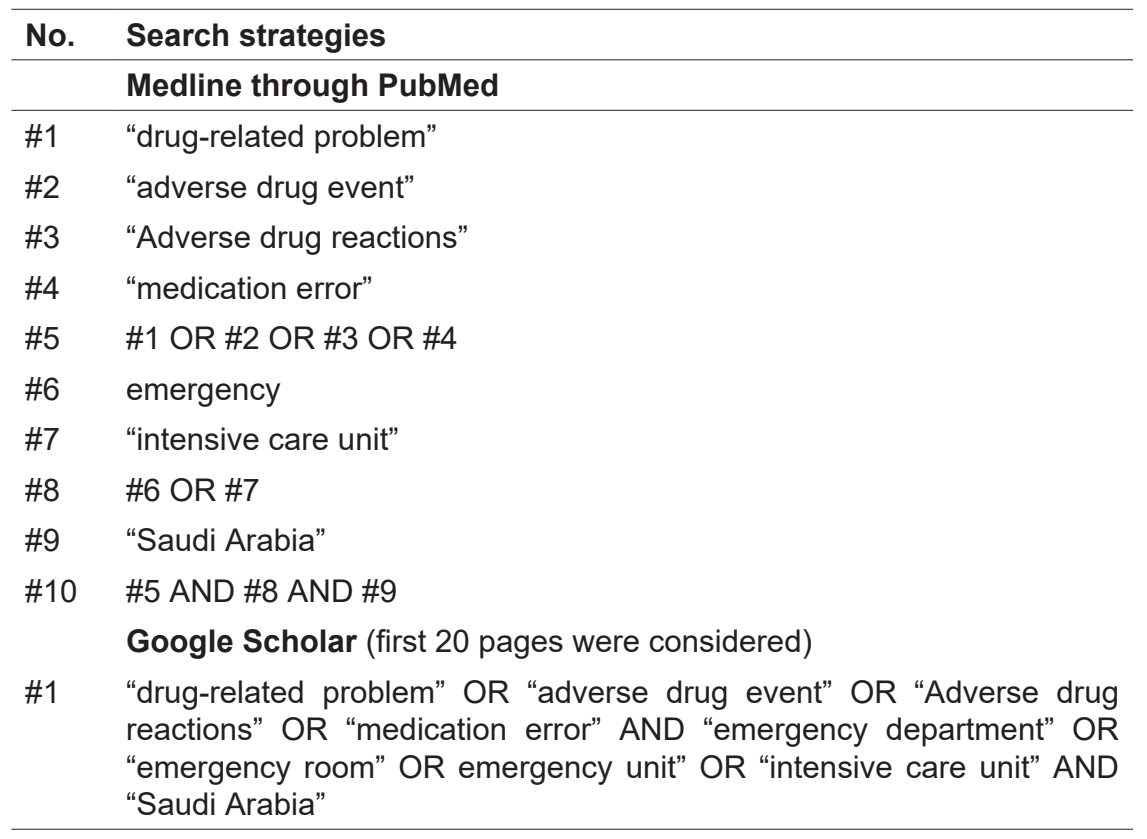

